\title{
Acute responsivity of the serotonergic system to S-citalopram and positive emotionality-the moderating role of the 5-HTTLPR
}

\author{
Catrin Wielpuetz *, Yvonne Kuepper, Phillip Grant, Aisha J. L. Munk and Juergen Hennig
}

Personality Psychology and Individual Differences, Department of Psychology, Justus-Liebig-University Giessen, Giessen, Germany

Edited by:

John J. Foxe, Albert Einstein College of Medicine, USA

\section{Reviewed by:}

Evdokia Anagnostou, University of

Toronto, Canada

Gerhard Stemmler,

Philipps-Universitaet Marburg,

Germany

*Correspondence:

Catrin Wielpuetz, Personality

Psychology and Individual

Differences, Department of

Psychology, Justus-Liebig-University

Giessen, Otto-Behaghel-Str. 10F,

D-35394 Giessen, Germany

e-mail: catrin.wielpuetz@psychol.

uni-giessen.de
According to the idea that the central serotonergic system has a modulatory function on behavior and personality in general, we aimed to highlight its association to habitual positive emotionality. In a placebo-controlled double-blind and randomized cross-over neuroendocrine challenge design ( $n=72$ healthy males) we investigated the association of the central serotonergic responsivity, 5-HTTLPR-genotype as well as their combined effects on positive emotionality. Regression analyses revealed an involvement of the serotonergic system in positive emotionality. There was, however, no direct association between positive emotionality and cortisol responses to S-citalopram; rather 5 -HTTLPR-genotype showed an association $(p<0.05)$. That is, positive emotionality scores increased with the number of s-alleles carried by the individuals. Most notable was the moderating role of 5-HTTLPR-genotype $(p<0.05)$ on the association between acute serotonergic responsivity and positive emotionality. Indeed, this association was only found in ss-homozygotes, in which the acute responsivity of the serotonergic system additionally seems to contribute to the level of positive emotionality $(r=0.70$, $p<0.05$ ). The findings correspond to previous research demonstrating that the 5-HTTLPR is not only involved in the negative-emotional aspects of behavior and temperament, but is associated, moreover, with positive affectivity-supporting the assumption of its valence-neutrality. In addition, our data are in line with the idea of possible influences of the 5-HTTLPR-genotype on early neuronal development. They also indicate the need for further studies in order to clearly elucidate the role of the serotonergic system and its subcomponents in the regulation of positive emotionality.

Keywords: S-citalopram, 5-HTTLPR, positive emotionality, serotonin, neuroendocrine challenge test

\section{INTRODUCTION}

The central serotonergic system controls a wide range of processes (e.g., Lucki, 1998), wherein it is thought to have general non-specific inhibitory effects (Spoont, 1992). Most research has focused on the involvement of serotonin in psychopathology and negative affectivity, wherefore its potential contribution to positive affectivity has mostly been disregarded.

In his neurobiological theory Depue explicitly links the serotonergic system to these inhibitory processes on the neural and behavioral level, presuming it to function as a thresholdmodulator facilitating the elicitation of avoidance- as well as approach-behavior in case of reduced functionality (Depue and Collins, 1999; Depue and Fu, 2011). It is, therefore, thought to be "valence-neutral" and should modulate negative as well as positive emotionality. On this background, the present study aims to further elucidate the role of interindividual variations in the functionality of the serotonergic system regarding the trait of positive emotionality-i.e., stable dispositions associated with frequent experiencing of positive affect, approach motivation and behavior, reflecting interindividual differences in underlying emotional response systems (Depue et al., 1994; Tellegen and Waller, 2008).
Eligible methods to assess the general activity of the central serotonergic system are neuroendocrine challenge paradigms, whereby the hormonal response to a serotonergic agonist indexes its net responsivity (Yatham and Steiner, 1993). Few serotonergic challenge-studies have reported data regarding traits of positive emotionality (i.e., extraversion), most of which have not shown a link between extraversion and serotonergic responsivity using different substances (e.g., Manuck et al., 1998; Flory et al., 2004; Brummett et al., 2008; Kuepper et al., 2010). Indeed, Reist et al. (1996) demonstrated a positive association of the cortisol response to paroxetin (indicating a diminished serotonergic responsivity) in healthy males. Further evidence stems from challenge-studies assessing mood over several consecutive days. While Zald and Depue (2001) showed a blunted prolactin response to fenfluramine to be associated with enhanced averaged negative as well as positive affect [i.e., the two independent dimensions of mood, as postulated by Watson et al. (1988)] in healthy males, Flory et al. (2004) only found an association with positive affect, albeit in opposite direction, in a considerably larger mixed-sex sample. Summarily, there are indications of an association of the responsivity of the serotonergic system with at 
least some aspects of positive emotionality; particularly when the affective-component is measured [i.e., indicated by moderately stable indicators of mood, measured over several weeks (Zald and Depue, 2001)].

Genetic variations could contribute to differences in serotonergic responsivity. One of the most intensively investigated serotonin-related polymorphisms is the 5-HTTLPR (serotonin transporter-gene-linked polymorphic region) within the promoter of the serotonin-transporter (5-HTT) gene (SCL6A4). The deletion/insertion of a repeat-element results in a short (s-allele) and a long allele (l-allele) (Lesch et al., 1996). Most research regarding the 5-HTTLPR and personality in healthy volunteers has stressed traits of negative emotionality (e.g., Munafo et al., 2009). Concerning positive emotionality, a meta-analysis by Munafo et al. (2003) concluded that there is no association with approach traits, which has been confirmed subsequently (Sen et al., 2004; Munafo et al., 2006; Kazantseva et al., 2008; Fox et al., 2009; Terracciano et al., 2010).

As temperamental traits are defined as emerging from a general sensitivity for trait-congruent emotional stimuli (e.g., Gray, 1982; Depue and Collins, 1999), studies assessing this responsiveness could additionally be consulted. Alongside an altered attention to unpleasant stimuli (Pergamin-Hight et al., 2012), some studies demonstrated that s-allele-carriers, unlike ll-homzygotes, also selectively attend to pleasant stimuli (Beevers et al., 2009, 2011; Fox et al., 2011). Neuroimaging studies underpin this association, showing heightened neuronal activation in response to negatively- (Munafo et al., 2008) as well as positively-valenced stimuli in s-allele-carriers (Canli et al., 2005; Herrmann et al., 2007; Klucken et al., 2012).

This greater responsiveness to both negative and positive stimuli in s-allele-carriers also seems to be evident regarding the impact of life events. Ss-homozygotes are disproportionally impaired more by negative life events (e.g., Uher and McGuffin, 2008; Karg et al., 2011), but also profit substantially more from the absence of negative life events - as reviewed by Belsky et al. (2009) — or a preponderance of positive life events (Taylor et al., 2006; Pluess et al., 2010; Kuepper et al., 2012).

These findings suggest that the s-allele of the 5-HTTLPR actually seems to be associated with a general "hypervigilance" (Homberg and Lesch, 2011) to emotional stimuli of negative as well as positive valence. Moreover, research on gene $\times$ environment $(\mathrm{G} \times \mathrm{E})$ interactions could explain why there is no direct association between the 5-HTTLPR-genotype and positive emotionality, thus highlighting the moderating role of the 5-HTTLPR-genotype.

We investigated the association between two indicators of serotonergic functionality (i.e., acute neuroendocrine response to S-citalopram and the 5-HTTLPR-genotype) and habitual positive emotionality, expecting a moderating effect of 5-HTTLPR-genotype. This was based on findings regarding $\mathrm{G} \times$ E interactions concerning psychological outcomes as well as first indications that serotonergic activity is especially influenced by environmental factors in s-allele-carriers (Bennett et al., 2002; Manuck et al., 2004). Thus, it is conceivable that the strength of an association between serotonergic functionality and positive emotionality varies depending on genotype. If the hypothesized effect is valid, a main effect of acute responsivity should be weak or absent, explaining previous inconclusive findings.

\section{MATERIALS AND METHODS PARTICIPANTS}

Participants were recruited at the University of Giessen and via announcements in a local magazine; offering $€ 150$ for participation. Seventy-two males were carefully selected on the basis of their 5-HTTLPR-genotype as well as a polymorphism in the TPH-2 gene (rs4570625; G-703T; for details see "Genotyping") and if they met the following criteria: Caucasian ethnicity, age between 18 and 33, right-handedness, non-smoker for at least 1 year, no current or history of psychiatric or physical disorders (i.e., neurological or chronic diseases), no current use of any medication, no drug or alcohol abuse, coffee-consumption below 8 cups per day and a body mass index (BMI) between 19 and 25.4. The listed criteria were assessed via self-report. Additionally, subjects with a Beck Depression Inventory-score above 17 were excluded (German translation, Hautzinger et al., 1995), and an adapted version of the Mini-DIPS (Margraf, 1994) with the screening items in written format was administered. If necessary, the respective part of the structured interview was conducted.

Four participants had to be excluded after study-participation because of missing data $(N=1)$ or abnormal measurement results in cortisol samples $(N=3)$. Therefore, the final data analyses are based on 68 participants (mean age $24.2 \pm 2.6$ years).

Before participating in the study, participants were fully informed about the objective of the study, the administered substance, and possible side effects of S-citalopram, and written informed consent was obtained. They were further instructed how to behave on the day of the testing-sessions as well as on the evening before; essentially to refrain from alcohol-, medicationor drug-use, go to bed before 12 p.m. and have lunch before 1 p.m. on the day of the testing-session. The study protocol was approved by the ethics committee of the German Association of Psychology (DGPs).

\section{PERSONALITY}

Positive Emotionality (PEM) was assessed through the brief form of the Multidimensional Personality Questionnaire (MPQBF, German translation: Angleitner et al., 1993). The MPQ-BF (Patrick et al., 2002) additionally measures Negative Emotionality and Constraint, with 155 items in total in a dichotomous format (true $=1$, false $=0$ ). The PEM-scale is comprised of four subscales: Wellbeing, Social Potency, Social Closeness, and Achievement. The total score is obtained by summing up the respective 36 items, yielding scores between 0 and 36 .

\section{PROCEDURE}

Participants were given $10 \mathrm{mg}$ S-citalopram (orally, Cipralex ${ }^{\circledR}$, Lundbeck, Germany) during one testing-session and placebo during the other in a double-blind randomized crossover-design. We chose a dosage of $10 \mathrm{mg}$, because prior studies showed a lack of side effects as well as an equal proportion of responders and non-responders in the cortisol response-a desirable prerequisite 
to investigate interindividual differences in the responsivity of the serotonergic system (Kuepper et al., 2006).

The interval between the two sessions was exactly 14 days (20 days in only one individual) to ensure a sufficient washout period according to the pharmacokinetics of S-citalopram (Sogaard et al., 2005). The sessions started either at 14:50 h, $15: 00 \mathrm{~h}, 15: 10 \mathrm{~h}$, or $15: 20 \mathrm{~h}$ to enable the testing of four participants per day.

On arrival, participants were seated in an upright position in comfortable arm chairs for the whole testing-session. To prevent boredom, they were allowed to read provided neutral magazines. After a familiarization-period of $15 \mathrm{~min}$ the baseline saliva sample was obtained, directly followed by the administration of either verum or placebo. Further cortisol samples for the challenge paradigm were collected $50 \mathrm{~min}$ after drug intake and then in subsequent $30 \mathrm{~min}$-intervals (samples 3-7). Before the second sample after $50 \mathrm{~min}$, participants completed one of two questionnaire-sets during each testing-session.

Because of the long testing-interval and to prevent side effects, participants were offered $100 \mathrm{ml}$ of water for the substanceintakes and, additionally, $50 \mathrm{ml}$ after cortisol samples 2, 5, and 7 as well as $100 \mathrm{ml}$ water and a soft pretzel after the third sample.

\section{SALIVARY CORTISOL AND RESPONSE MEASURE}

Saliva samples were collected with Salivettes ${ }^{\circledR}$ according to the standard-procedure (Sarstedt, Nuembrecht, Germany). After every test day saliva samples were centrifuged $(10 \mathrm{~min}, 4000 \times \mathrm{g})$ and frozen immediately at $-30^{\circ} \mathrm{C}$ for later use. Concentrations of salivary cortisol levels were determined through use of a commercial enzyme immunoassay (IBL, Hamburg, Germany). All analyses were performed in duplicates using a fully automated analyzer (Adaltis, NexGen Four, Freiburg, Germany). All samples were analyzed within the same lot to avoid inter-assay-variation due to differences in different charges. The intra-assay-variation (CV) was lower than $5 \%$.

In order to have a single measure for the serotonergic responsivity, we calculated the placebo-corrected area under the response curve (AUC-R) for the cortisol response (Pruessner et al., 2003). A preliminary analysis of the cortisol responses showed significant differences between the cortisol responses under placebo and S-citalopram for samples $4-6$ ( $p s \leq 0.008)$ and a trend for sample $7(p=0.066)$. Therefore, areas under the curves (AUCs) were calculated for samples 3-7, using sample 3 as baseline. Finally, the placebo corrected AUC-R was determined by subtracting the AUC for placebo from the AUC for S-citalopram (Figure 1).

\section{ADVERSE SIDE EFFECTS}

To monitor possible side effects, participants' somatic symptoms were assessed using a visual analog scale (VAS) _ ranging from 1 (no, not at all) to 100 (yes, completely)—with each saliva sample. The somatic symptom items comprised typical adverse side effects of S-citalopram, i.e., nausea, drowsiness, nasal congestion, dizziness, diarrhea, headache, mouth dryness and blurred vision. For statistical analysis regarding side effects, all somatic symptoms were summed up, separate for each time point (1-7). There was neither a significant effect of substance compared to

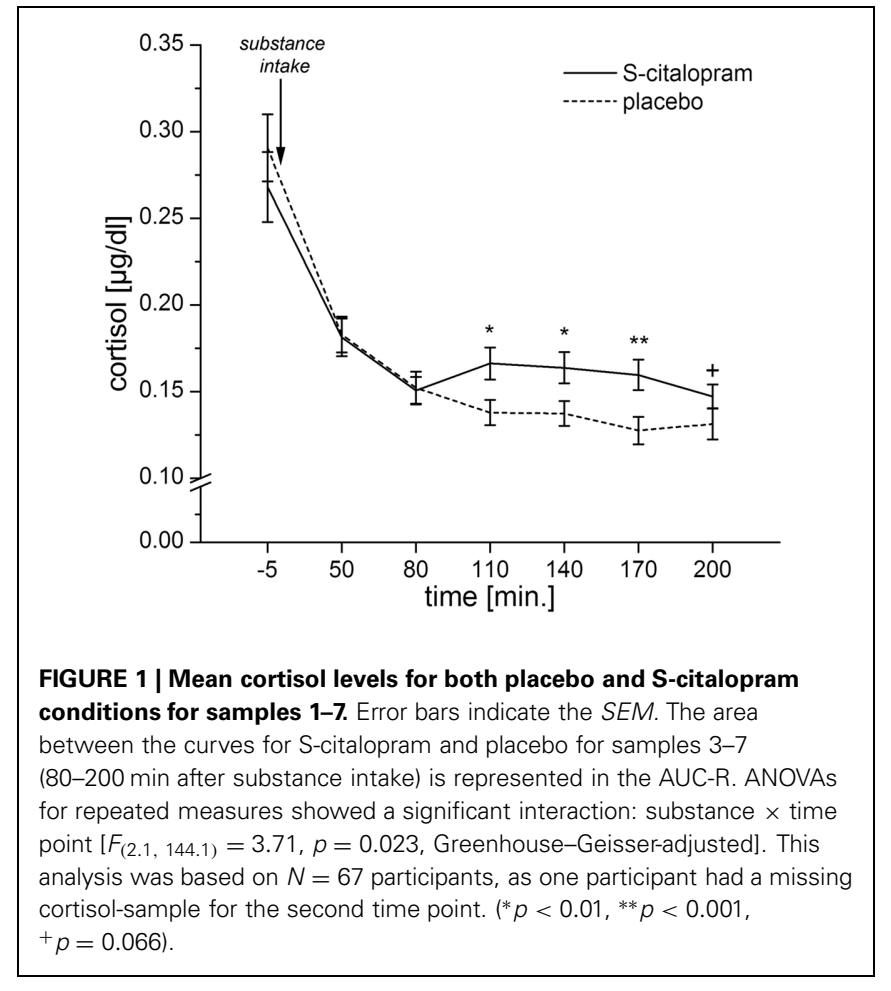

placebo $\left[F_{(1,67)}=1.68, p=0.20\right]$ nor a significant interaction between substance and time point $\left[F_{(4.2,278.3)}=0.76, p=0.56\right]$. Therefore, there were no adverse side effects of S-Citalopram, which was expected, due to the very low dosage of $10 \mathrm{mg}$ (Kuepper et al., 2006).

\section{GENOTYPING}

DNA was extracted from buccal cells using a standard commercial extraction kit (High Pure PCR Template Preparation Kit; Roche, Mannheim, Germany) in a MagNA Pure LC System (Roche). Genotyping for the 5-HTTLPR was performed in our lab as described previously by Alexander et al. (2009).

Participants were invited according to their genotype for 5HTTLPR as well TPH-2 rs4570625, aiming at 4 equal cells. As part of another study, it was intended to investigate the joint influence of these two polymorphisms. Accordingly, participants were classified into s-allele-carriers or ll-homozygotes for the 5-HTTLPR (frequencies see Table 1) and T-allele-carriers vs. GG-homozygotes for the rs4570625.

Table 1 | Sample sizes, age, BMI, and AUC-R separated for 5-HTTLPR-genotype-groups (ss, sl, and II).

\begin{tabular}{llll}
\hline \multicolumn{1}{l}{ ss } & sl & \multicolumn{1}{l}{ II } \\
\hline$n$ & \multicolumn{1}{l}{10} & \multicolumn{1}{l}{22} & \multicolumn{1}{l}{36} \\
age & $24.40 \pm 2.59$ & $24.41 \pm 2.93$ & $24.06 \pm 2.46$ \\
BMI $\left(\mathrm{kg} / \mathrm{m}^{2}\right)$ & $23.33 \pm 1.76$ & $22.85 \pm 1.87$ & $22.53 \pm 1.80$ \\
AUC-R & $2.75 \pm 7.78$ & $3.04 \pm 5.38$ & $3.68 \pm 8.19$ \\
\hline
\end{tabular}

Means $\pm S D$ s for age, BMI, and AUC-R are reported. 


\section{DATA ANALYSES}

To test for possible confounding factors (age, BMI), analyses of variance (ANOVA) or correlation analyses were conducted. Normal distributions of the PEM-scores and the AUC-R were verified through the Kolmogorov-Smirnov-test.

We tested for relevant predictors of PEM, using regression analyses, which enabled us to investigate potential mediator or moderator effects of 5-HTTLPR-genotype (more precisely, linear effects of an individual's number of s-alleles) and AUC-R (Baron and Kenny, 1986). In order to prevent problems of multicollinearity regarding the interaction term, AUC-R-values were standardized (AUC-R ) (Aiken and West, 1991).

First we conducted a regression analysis with only 5-HTTLPRgenotype entered to predict the AUC-R in order to test for the mediating effect.

In a second analysis, a hierarchical regression analysis (stepwise) was performed. Since neither PEM-scores nor 5-HTTLPRgenotype were associated with age and BMI (see results), these variables were not included. 5 -HTTLPR-genotype $(1=11,2=\mathrm{sl}$, $3=$ ss, indicating an increasing number of 5-HTTLPR s-alleles), standardized AUC-R values $\left(A U C-\mathrm{R}_{z}\right.$ ) and the interaction term 5-HTTLPR-genotype $\times$ AUC- $\mathrm{R}_{z}$ were entered consecutively. Post-hoc analyses for significant predictors were conducted using ANOVAs or correlation analyses. Results were considered significant with $p<0.05$ (two-tailed).

\section{RESULTS}

Prior to the main analysis we tested whether 5-HTTLPR-genotype or AUC-R was associated with age or BMI. 5-HTTLPR-genotypegroups did not differ with respect to age $\left[F_{(2,65)}=0.15, p=\right.$ $0.86]$ or BMI $\left[F_{(2,65)}=0.80, p=0.46\right]$ (see Table 1). Likewise, the AUC-R was not significantly associated with age $(r=0.07$, $p=0.55)$ or BMI $(r=0.11, p=0.38)$.

PEM-scores $(M=31.11, S D=8.23)$ as well as the AUC-R $(M=2.98, S D=7.06)$ were distributed normally (PEM: $Z=$ $0.81, p=0.54$; AUC-R: $Z=0.61, p=0.76$ ).

Regression analysis revealed no significant association between 5-HTTLPR-genotype (i.e., number of s-alleles) and AUC-R $\mathrm{R}_{z}[\beta=$ $\left.0.01 ; R=0.04, F_{(1,66)}=0.13, p=0.72, R^{2}=0.002\right]$. In order to exclude the possibility that differences between the genotypegroups were non-linear (and hence would not be detected by regression analyses), an ANOVA was performed. But likewise, there were no significant differences regarding AUC-R values between 5-HTTLPR-genotype-groups $\left[F_{(2,65)}=0.07, p=0.94\right.$; also see Table 1]. Consequently, it could be ruled out that the AUC-R functions as a mediator of a possible association of 5-HTTLPR-genotype and PEM.

A hierarchical regression analysis was conducted to examine whether markers of serotonergic system activity (i.e., 5-HTTLPR, AUC-R) predict PEM. Since age and BMI were not associated with either predictor and, additionally, were not associated with PEMscores themselves (age: $r=-0.10, p=0.43$; BMI: $r=-0.01$, $p=0.96)$, both variables were disregarded for further analyses. The first significant model $\left[R=0.24, F_{(1,66)}=4.2, p=0.045\right.$; $\left.R^{2}=0.059\right]$ showed only the 5-HTTLPR-genotype to be a significant predictor of PEM-scores $(\beta=0.24, p=0.045)$, whereas the AUC-R $Z$ was non-significant and hence excluded $(\beta=0.23$, $p=0.053)$. Inclusion of the interaction term lead to a second significant model $\left[R=0.35, F_{(2,65)}=4.5, p=0.014 ; R^{2}=\right.$ $\left.0.122, \Delta R^{2}=0.063\right]$, rendering the interaction term 5-HTTLPR $\times$ AUC- $R_{z}$ significant $(\beta=0.25, p=0.034)$ and thereby minimally reducing the weight of the 5-HTTLPR-genotype $(\beta=0.23$, $p=0.053)$. The $\mathrm{AUC}-\mathrm{R}_{z}$ still remained excluded $(\beta=0.03$, $p=0.90)$.

To further evaluate the results, post-hoc analyses were performed. Though the regression analysis revealed a linear association between the 5-HTTLPR-genotype and PEM-scores, differences between 5-HTTLPR-genotype-groups were not significant $\left[F_{(2,65)}=2.1, p=0.14\right]$, while the linear association can clearly be seen in the data (see Figure 2).

Since the significant interaction term indicates 5-HTTLPRgenotype specific associations between the AUC- $\mathrm{R}_{Z}$ and PEMscores, simple correlation analyses were performed separated for 5-HTTLPR-genotype-groups. We found a significantly positive correlation between AUC-R and PEM-scores for the sshomozygotes $(r=0.70, p=0.023)$ but no associations for either the sl-heterozygotes $(r=0.25, p=0.27)$ or the ll-homozygotes $(r=0.17, p=0.33)$ (see Figure 3).

Although the effect of the AUC-R was not significant, we repeated our analysis with keeping the AUC-R in the regression model. When entering both the AUC-R and the interaction term simultaneously, neither reached significance [AUC-R: $\beta=0.03$, $p=0.91$; AUC-R $\times 5$-HTTLPR: $\beta=0.23, p=0.39 ; R=0.35$, $\left.F_{(3,64)}=3.0\right]$, indicating only the 5-HTTLPR-genotype as a significant predictor of positive emotionality $(\beta=0.24, p=0.045)$.

To get a clearer picture of the nature of associations depicted in our first regression model, however, we additionally analyzed the correlation between the AUC-R and positive emotionality only within the group of l-allele-carriers (i.e., sl and ll). Interestingly, we observed no association between the AUC-R and positive

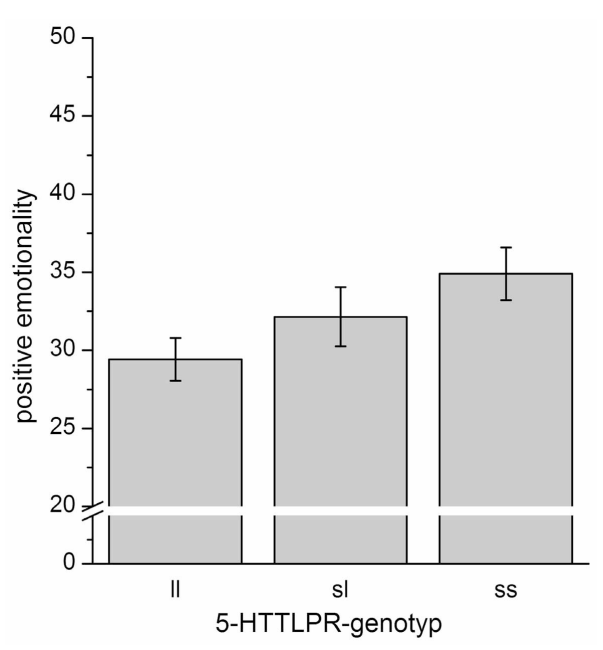

FIGURE 2 | Mean scores for positive emotionality separated for 5-HTTLPR-genotype. Error bars indicate the SEM. While the ANOVA was insignificant, when contrasting only ss-homozygotes vs. Il-homozygotes, we detected a trend for significantly increased scores of positive emotionality in ss-homozygotes $\left[T_{(65)}=1.89, p=0.063\right]$. 

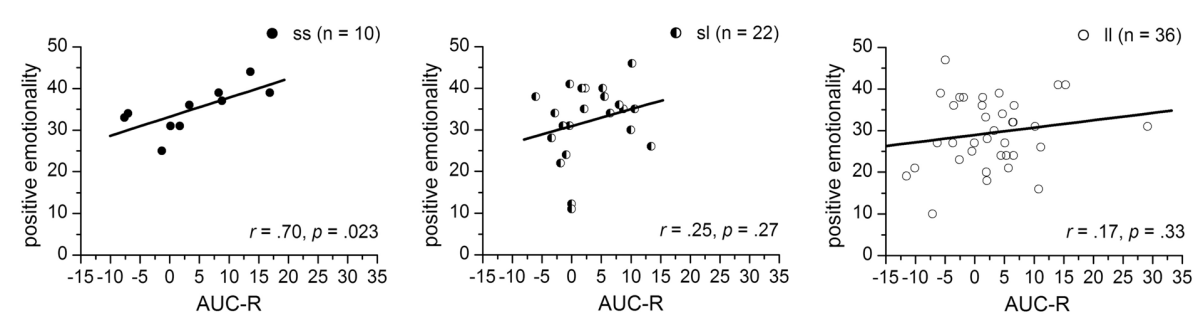

FIGURE 3 | Correlations between the AUC-R (raw data) and positive emotionality separated for 5-HTTLPR-genotype: ss, sl, and II.

emotionality within this group $(r=0.18, p>0.15)$. This clearly indicates that the aforementioned interaction term is based on the associations between AUC-R and positive emotionality within sshomozygotes $(r=0.70, p=0.023)$. We are convinced that this alternative strategy of data analysis turned out to confirm our previous regression analysis and the relevance of the interaction term.

\section{DISCUSSION}

Based on the assumption that the central serotonergic system has a non-specific modulatory function on behavior (Spoont, 1992; Depue and Collins, 1999) and not exclusively on avoidance behavior and negative affect, we aimed to further elucidate its contribution to positive emotionality.

We did not find a direct association between positive emotionality and the acute functionality of the serotonergic system but somewhat remarkably with the 5-HTTLPR-genotype. That is, an increasing number of s-alleles was associated with increasing positive emotionality. Most notable, however, was the hypothesized moderating role of the 5-HTTLPR-gentoype on the association between acute serotonergic activity and positive emotionality. Such an association was found exclusively in ss-homozygotes. Thereby, it seems that only in ss-homozygotes the acute serotonergic system activity contributes additionally to the degree of positive emotionality.

Furthermore, our design allowed us to investigate the influence of 5-HTTLPR-genotype on central serotonergic responsivity. In vitro studies indicate a functional impact of 5-HTTLPR-genotype, with a higher transcriptional efficiency of the 5-HTT-gene as well as increased serotonin reuptake for the 1-allele compared to the s-allele (Lesch et al., 1996; Greenberg et al., 1999). Corresponding PET- and SPECT-studies, however, yielded contradictory results. Considering only those studies using $\left[{ }^{11} \mathrm{C}\right] \mathrm{DASB}$, the radioligand considered to be most appropriate (Willeit and Praschak-Rieder, 2010), some found an increased serotonin transporter binding in ll-homozygotes compared to s-allele-carriers (Praschak-Rieder et al., 2007; Reimold et al., 2007; Kalbitzer et al., 2009), while Murthy et al. (2010), using the largest sample, could not show a functional influence. Also Christian et al. (2009) did not find any association in non-human primates, likewise pointing to no unequivocal evidence for a functional influence in vivo.

Furthermore, our results are in line with those neuroendocrine challenge studies in healthy participants finding no or only weak evidence for functional consequences (Manuck et al., 2004; Smith et al., 2004; Wong et al., 2008). Only Whale et al. (2000) demonstrated a blunted prolactin response for ss-homozygotes. They, however, used clomipramine, which does not act selectively only on the serotonergic system (Tatsumi et al., 1997). Thus, evidence suggests that the 5-HTTLPR does not appear to have robust functional consequences in vivo.

In addition, certain aspects of our study design would have been advantageous to detect a putative association. With Scitalopram we used the most specific SSRI (Owens et al., 2001) currently available in a placebo-controlled design. This ideally ensures exclusive assessment of net responsivity of the serotonergic system. Furthermore, our sample was considerably larger than most of the studies cited and consisted of healthy males only. Thereby, we excluded confounding effects of varying estrogen levels across the menstrual cycle that exert influence on the hypothalamus as well as the serotonergic system (McEwen, 2001). In addition, the sample consisted of comparably young participants, which excluded an influence of age on the serotonin transporter binding potential as shown by Kalbitzer et al. (2009).

Nonetheless, we showed positive emotionality to increase with the number of s-alleles. This finding was remarkable, since nearly no study has demonstrated such an association when personality was measured (e.g., Lesch et al., 1996; Sen et al., 2004; Terracciano et al., 2010). This might be explained by two aspects. Firstly, while most of the respective studies (e.g., Lesch et al., 1996; Terracciano et al., 2010) used the NEO-PI-R (Costa and McCrae, 1992), we assessed positive emotionality rather than extraversion through the MPQ. The MPQ is considered to be an emotional-temperament inventory reflecting interindividual differences in the underlying emotional response systems (Tellegen, 1985; Patrick et al., 2002; Tellegen and Waller, 2008) of the traits of positive and negative emotionality that are conceptually parallel with Depue's postulated affective personality dimensions (Depue and Lenzenweger, 2001). This means that high scores in this scale for positive emotionality would indicate a heightened responsiveness to emotional stimuli. Specifically, such an increased reactivity for positive as well as negative emotional stimuli has been demonstrated in s-allele-carriers several times (e.g., Canli et al., 2005; Herrmann et al., 2007; Beevers et al., 2009). One could, insofar, speculate that the MPQ more closely depicts emotional responsiveness and reflects its biological underpinnings more adequately. Moreover, there is evidence that NEO extraversion and MPQ positive emotionality do not represent the same construct (Church, 1994). 
A second explanation might be the highly selected sample. We carefully made sure to exclude participants with psychiatric disorders. When bearing $\mathrm{G} \times \mathrm{E}$ interactions in mind, it could be hypothesized that by excluding volunteers with higher depression symptoms we especially excluded s-allele-carriers with predominantly negative life events in favor of s-allele-carriers with a preponderance of positive life events and thus possibly higher positive emotionality. In other words, studies including participants with higher scores in neuroticism may be at risk of masking effects for positive emotionality. This hypothesis is further supported by Minelli et al. (2011), who demonstrated that associations between the 5-HTTLPR and anxiety-related traits only exist in samples heterogenous regarding the mental health status.

In conclusion, there is evidence that there is, indeed, a detectable albeit weak association between 5-HTTLPR-genotype and positive emotionality; whereby further research is needed to disentangle the specific effects of those factors mentioned above, which seem to influence the detection of this association. Hereof, life events appear to be an especially promising candidate.

The influence of 5-HTTLPR-genotype was not mediated by the acute responsivity of the serotonergic system. Instead, the 5-HTTLPR-genotype took on the role of a moderator; i.e., the functionality of the serotonergic system was positively linked to positive emotionality in ss-homozygotes only.

An elevated cortisol response can be interpreted as indexing a reduced overall activity of the serotonergic system. The putative reason for an elevated cortisol response is an upregulation or sensitization of postsynaptic receptors, caused by a habitually diminished serotonin release (Hennig et al., 2005). Within this line of reasoning, our results support Depue's theory, which postulates that a reduced serotonergic functionality lowers the threshold for response elicitation, which, in turn, should manifest in temperamental traits (Depue and Collins, 1999). Importantly, however, we demonstrated this effect in ss-homozygotes only.

At this point, one could only speculate why differences in the serotonergic responsivity are only linked to personality in ss-homozygotes. Despite the presumably lacking functional consequences of the 5-HTTLPR-genotype in vivo, evidence nevertheless suggests that it is associated with emotional processing and personality even in healthy participants.

To integrate these divergent findings, it seems plausible that the 5-HTTLPR-genotype exerts some of its effects primarily during the ontogeny of the central nervous system. Nordquist and Oreland (2010) as well as Whitaker-Azmitia (2005) have summarized findings regarding the neurotrophic effects of serotonin. They argue that an excess of serotonin during early neuronal development-which might be caused by the short variant of the 5-HTTLPR - could lead to morphological and functional changes, including circuits involved in emotional processing as well as in serotonergic neurons themselves, thereby likely leading to behavioral and emotional alterations in later life.

This reasoning fits to the observed alterations in neuronal circuits associated with emotional processing (e.g., Hariri et al.,
2002; Canli et al., 2005; Heinz et al., 2005; Pezawas et al., 2005), which are likely to account for the hypervigilance in s-allelecarriers (Homberg and Lesch, 2011). Based on these considerations, one might interpret our data as indicating that acute variations in the functionality of the serotonergic system, indeed, only modulate positive emotionality in those subjects who are genetically predisposed. Underpinning this, there is evidence that 5-HTTLPR-genotype moderates the effects of, e.g., acute tryptophan depletion on mood and behavior (Marsh et al., 2006; Neumeister et al., 2006; Markus and Firk, 2009; Markus and De Raedt, 2011), pointing to a higher vulnerability to alterations in the serotonergic neurotransmission in ss-homozygotes.

The main reason for this study regarding the association of the serotonergic system and positive emotionality was Depue's postulate (Depue and Collins, 1999) of the serotonergic system as a general threshold modulator. One could further speculate on an essential contribution of the oxytocinergic system to positive emotionality, not least because Depue (Depue and Lenzenweger, 2001; Depue and MorroneStrupinsky, 2005; Depue and Fu, 2011) also linked components of positive emotionality-namely affiliation-to the oxytocinergic system.

Indeed, there a several additional arguments that suggest that effects of oxytocin could have, at least partially, contributed to our results. Firstly, there is a co-localization of oxytocin-labeled cells and serotonin-transporter-labeled fibers in the paraventricular (PVN) and supraoptic nuclei (SON) of the hypothalamus (Emiliano et al., 2007). Secondly, oxytocin-release is influenced by acute serotonergic neurotransmission: exogenous serotonin as well as several serotonin-receptor agonists (primarily via $5-\mathrm{HT}_{1 \mathrm{~A}}$, $5-\mathrm{HT}_{2} \mathrm{C}$, and $5-\mathrm{HT}_{4}$ receptors) lead to an increase in plasma oxytocin levels (Jorgensen et al., 2003). Importantly, the acute administration of citalopram also increases the concentration of oxytocin in the plasma (Uvnas-Moberg et al., 1999) as well as levels of oxytocin-mRNA within the magnocellular regions of the PVN (Hesketh et al., 2005). Regarding a possible influence on the cortisol-release to S-citalopram in our study, there is evidence that central oxytocin-release leads to attenuated endocrine responses to acute stress; i.e., glucocorticoids and ACTH, as was shown in studies administering oxytocin directly (Windle et al., 1997; Heinrichs et al., 2003; Parker et al., 2005; Ditzen et al., 2009).

The interaction of both systems, therefore, could have contributed to the association of positive emotionality with the cortisol-response to S-citalopram to some degrees (also, if in ss-homozygotes only). The exact consequences of the influence of oxytocin are, however, hard to specify (because of a contribution of levels of both neurotransmitters as well as various involved receptors). One could only speculate, whether oxytocinergic influences also contribute to our association of 5-HTTLPR-genotype with positive emotionality, which cannot be ruled out; not least due to additional neurodevelopmental effects of serotonin on the oxytocinergic system (Whitaker-Azmitia, 2005). Future research is needed to allow further conclusions in this respect (e.g., measures of plasma oxytocin-levels in a neuroendocrine challenge-paradigm). 
Another point to keep in mind when interpreting our data, is that in light of the postulated general hypervigilance associated with the 5-HTTLPR s-allele (Homberg and Lesch, 2011), as well as Depue's understanding of the serotonergic system as a threshold modulator for both, approach and avoidance (e.g., Depue and Collins, 1999), one would expect similar results for the personality traits of negative emotionality. Therefore, we reanalyzed our data for negative emotionality (also assessed using the MPQ). Importantly, positive and negative emotionality are assumed to be two independent dimensions (e.g., Tellegen and Waller, 2008), which is supported by our data $(r=-0.14$, $p=0.24)$. The regression analysis did not show the 5-HTTLPRgenotype, the AUC-R or the interaction term to be associated with negative emotionality (for all $\beta s, p s>0.50$ ). Though somewhat surprising, this result clarifies that the association of the serotonergic predictors of positive emotionality do not simply reflect an association with negative emotionality, but rather a distinct association with positive emotionality. Nevertheless, based on the above mentioned assumptions, one would rather have expected associations to both, positive and negative emotionality. Returning to our foregoing explanation for the results regarding positive emotionality and the 5-HTTLPR-genotype (i.e., the highly selected sample), this also seems to explain this possible lack of association. Following this explanation, we potentially excluded especially 5-HTTLPR s-allele-carriers with a high incidence of negative life events that display higher scores in neuroticism (e.g., Kuepper et al., 2006; Pluess et al., 2010) and more depression symptoms (e.g., Caspi et al., 2003; Taylor et al., 2006). Likewise, this is in accordance with the results by Minelli et al. (2011), showing that the 5-HTTLPR-genotype is only associated with anxiety-related traits in heterogenous samples.

Certain limitations of our study must be kept in mind: as far as molecular genetic studies are concerned, our sample was relatively small, and we only tested males. Replications are therefore clearly needed, especially in females. Furthermore, our reasoning concerning the underlying mechanisms is speculative, and future research should shed light on factors that

\section{REFERENCES}

Aiken, L. S., and West, S. G. (1991). Multiple Regression: Testing and Interpreting Interactions. Newbury Park, CA: Sage.

Alexander, N., Kuepper, Y., Schmitz, A., Osinsky, R., Kozyra, E., and Hennig, J. (2009). Gene-environment interactions predict cortisol responses after acute stress: implications for the etiology of depression. Psychoneuroendocrinology 34, 1294-1303. doi: 10.1016/j. psyneuen.2009.03.017

Angleitner, A., Langert, R., Schilling, J., and Spinath, F. M. (1993). Deutsche Form des Multidimensional Personality Questionnaire (MPQ). Bielefeld: University Bielefeld.

Baron, R. M., and Kenny, D. A. (1986).

The moderator mediator variable distinction in social psychologicalresearch-conceptual, strategic, and statistical considerations. J. Pers. Soc. Psychol. 51, 1173-1182. doi: $\quad 10.1037 / 0022-3514.51 .6$. 1173

Beevers, C. G., Marti, C. N., Lee, H. J., Stote, D. L., Ferrell, R. E., Hariri, A. R., et al. (2011). Associations between serotonin transporter gene promoter region (5-HTTLPR) polymorphism and gaze bias for emotional information. J. Abnorm. Psychol. 120, 187-197. doi: 10.1037/a0022125

Beevers, C. G., Wells, T. T., Ellis, A. J., and McGeary, J. E. (2009). Association of the serotonin transporter gene promoter region (5-HTTLPR) polymorphism with biased attention for emotional

(a) foster the association between the 5-HTTLPR and positive emotionality and (b) contribute to the acute serotonergic functionality that in turn could also shape personality traits. Reasonable candidates would be life events or other genetic variations.

Initial evidence for an influence of living conditions stems from a study by Manuck et al. (2004). They demonstrated that the association between the prolactin response to fenfluramine and the socio-economic status is moderated by 5 -HTTLPR-genotype. This finding is further supported by Bennett et al. (2002), who found that the influence of early rearing conditions on the concentration of the serotonin metabolite 5-hydroxyindolacetic acid (5-HIAA) in the cerebrospinal fluid is moderated by the rh5HTTLPR-genotype in rhesus macaques.

Beyond this, further research should investigate the stability of the responsivity of the serotonergic system, which seems to be influenced by life events.

To our knowledge, this was the first study to specifically investigate the combined effects of both stable genetic variations and the acute responsivity of the serotonergic system on variations in positive emotionality. According to Depue, a diminished serotonergic functionality should ultimately amplify both positive and negative emotionality (Depue and Collins, 1999). Our results partly support this assumption in that ss-homozygotes manifest the highest positive emotionality. Furthermore, at least in ss-homozygotes, a reduced serotonergic functionality is, in turn, associated with higher positive emotionality. The results highlight the need to focus not only on negative affectivity and related processes but also on positive affectivity to fully understand the role of the serotonergic system.

\section{ACKNOWLEDGMENTS}

This study has been supported by the German Research Foundation (DFG, HE 2443/13-1). The authors would like to thank Cornelia Meineke for her technical assistance as well as Johanna Triebel, Ann-Kathrin Kreuder, and Marcus Buerger, for their help in acquiring participants for this study.

stimuli. J. Abnorm. Psychol. 118 670-681. doi: 10.1037/a0016198

Belsky, J., Jonassaint, C., Pluess, M., Stanton, M., Brummett, B., and Williams, R. (2009). Vulnerability genes or plasticity genes? Mol. Psychiatry 14, 746-754. doi: 10.1038/mp.2009.44

Bennett, A. J., Lesch, K. P., Heils, A., Long, J. C., Lorenz, J. G., Shoaf, S. E., et al. (2002). Early experience and serotonin transporter gene variation interact to influence primate CNS function. Mol. Psychiatry 7, 118-122. doi: 10.1038/sj.mp. 4000949

Brummett, B. H., Boyle, S. H., Kuhn, C. M., Siegler, I. C., and Williams, R. B. (2008). Associations among central nervous system serotonergic function and neuroticism are moderated by gender. Biol. Psychol. 78, 200-203. doi: 10.1016/j. biopsycho.2008.03.002

Canli, T., Omura, K., Haas, B. W., Fallgatter, A., Constable, R. T., and Lesch, K. P. (2005). Beyond affect: a role for genetic variation of the serotonin transporter in neural activation during a cognitive attention task. Proc. Natl. Acad. Sci. U.S.A. 102, 12224-12229. doi: 10.1073/pnas.0503880102

Caspi, A., Sugden, K., Moffitt, T. E., Taylor, A., Craig, I. W., Harrington, H., et al. (2003). Influence of life stress on depression: moderation by a polymorphism in the 5 -HTT gene. Science 301, 386-389. doi: 10.1126/science. 1083968

Christian, B. T., Fox, A. S., Oler, J. A., Vandehey, N. T., Murali, D., 
Rogers, J., et al. (2009). Serotonin transporter binding and genotype in the nonhuman primate brain using [C-11]DASB PET. Neuroimage 47, 1230-1236. doi: 10.1016/j.neuroimage.2009.05.090

Church, A. T. (1994). Relating the tellegen and 5-factor models of personality structure. J. Pers. Soc. Psychol. 67, 898-909. doi: 10.1037/00223514.67.5.898

Costa, P. T. Jr., and McCrae, R. R. (1992). Revised NEO Personality Inventory and NEO Five Factor Inventory Professional Manual. Odesssa, FL: Psychological Assessment Resources.

Depue, R. A., and Collins, P. F. (1999). Neurobiology of the structure of personality: dopamine, facilitation of incentive motivation, and extraversion. Behav. Brain Sci. 22, 491-517. doi: 10.1017/S0140525X99002046

Depue, R. A., and Fu, Y. (2011). Neurogenetic and experiential processes underlying major personality traits: implications for modelling personality disorders. Int. Rev. Psychiatry 23, 258-281. doi: 10.3109/09540261.2011.599315

Depue, R. A., and Lenzenweger, M. F. (2001). "A neurobehavorial dimensional model," in Handbook of Personality Disorders: Theory, Research and Treatment, ed W. J. Livesley (New York, NY: The Guilford Press), 136-174.

Depue, R. A., Luciana, M., Arbisi, P., Collins, P., and Leon, A. (1994). Dopamine and the structure of personality - relation of agonistinduced dopamine activity to positive emotionality. J. Pers. Soc. Psychol. 67, 485-498. doi: 10.1037/0022-3514.67.3.485

Depue, R. A., and Morrone-Strupinsky, J. V. (2005). Modeling human behavioral traits and clarifying the construct of affiliation and its disorders. Behav. Brain Sci. 28, 371-395. doi: 10.1017/S0140525X0543006X

Ditzen, B., Schaer, M., Gabriel, B., Bodenmann, G., Ehlert, U., and Heinrichs, M. (2009). Intranasal oxytocin increases positive communication and reduces cortisol levels during couple conflict. Biol. Psychiatry 65, 728-731. doi: 10.1016/j.biopsych.2008.10.011

Emiliano, A. B. F., Cruz, T., Pannoni, V., and Fudge, J. L. (2007). The interface of oxytocin-labeled cells and serotonin transporter-containing fibers in the primate hypothalamus: a substrate for SSRIs therapeutic effects? Neuropsychopharmacology 32, 977-988. doi: 10.1038/sj.npp. 1301206
Flory, J. D., Manuck, S. B., Matthews, K. A., and Muldoon, M. F. (2004). Serotonergic function in the central nervous system is associated with daily ratings of positive mood. Psychiatry Res. 129, 11-19. doi: 10.1016/j.psychres.2004.06.010

Fox, E., Ridgewell, A., and Ashwin, C. (2009). Looking on the bright side: biased attention and the human serotonin transporter gene. Proc. $R$. Soc. B Biol. Sci. 276, 1747-1751. doi: 10.1098/rspb.2008.1788

Fox, E., Zougkou, K., Ridgewell, A., and Garner, K. (2011). The serotonin transporter gene alters sensitivity to attention bias modification: evidence for a plasticity gene. Biol. Psychiatry 70, 1049-1054. doi: 10.1016/j.biopsych.2011.07.004

Gray, J. A. (1982). The Neuropsychology of Anxiety: An Enquiry into the Functions of the Septo-Hippocampal System. New York, NY: Oxford University Press.

Greenberg, B. D., Tolliver, T. J., Huang, S. J., Li, Q., Bengel, D., and Murphy, D. L. (1999). Genetic variation in the serotonin transporter promoter region affects serotonin uptake in human blood platelets. Am. J. Med. Genet. 88, 83-87.

Hariri, A. R., Mattay, V. S., Tessitore, A., Kolachana, B., Fera, F., Goldman, D., et al. (2002). Serotonin transporter genetic variation and the response of the human amygdala. Science 297, 400-403. doi: 10.1126/science.1071829

Hautzinger, M., Bailer, M., Worall, H., and Keller, F. (1995). BeckDepressions-Inventar (BDI); Testhandbuch. Bern: Hans Huber.

Heinrichs, M., Baumgartner, T., Kirschbaum, C., and Ehlert, U. (2003). Social support and oxytocin interact to suppress cortisol and subjective responses to psychosocial stress. Biol. Psychiatry 54, 1389-1398. doi: 10.1016/S0006-3223(03)00465-7

Heinz, A., Braus, D. F., Smolka, M. N., Wrase, J., Puls, I., Hermann, D. et al. (2005). Amygdala-prefrontal coupling depends on a genetic variation of the serotonin transporter. Nat. Neurosci. 8, 20-21. doi: 10.1038/nn1366

Hennig, J., Reuter, M., Netter, P., Burk, C., and Landt, O. (2005). Two types of aggression are differentially related to serotonergic activity and the A779C TPH polymorphism. Behav. Neurosci. 119, 16-25. doi: 10.1037/0735-7044.119.1.16

Herrmann, M. J., Huter, T., Muller, F., Muhlberger, A., Pauli, P., Reif, A., et al. (2007). Additive effects of serotonin transporter and tryptophan hydroxylase-2 gene variation on emotional processing. Cereb. Cortex 17, 1160-1163. doi: 10.1093/cercor/bhl026

Hesketh, S., Jessop, D. S., Hogg, S., and Harbuz, M. S. (2005) Differential actions of acute and chronic citalopram on the rodent hypothalamic-pituitary-adrenal axis response to acute restraint stress. J. Endocrinol. 185, 373-382. doi: 10.1677/joe.1.06074

Homberg, J. R., and Lesch, K. P. (2011). Looking on the bright side of serotonin transporter gene variation. Biol. Psychiatry 69, 513-519. doi: 10.1016/j.biopsych.2010.09.024

Jorgensen, H., Riis, M., Knigge, U., Kjaer, A., and Warberg, J. (2003). Serotonin receptors involved in vasopressin and oxytocin secretion. J. Neuroendocrinol 15, 242-249. doi: 10.1046/j.1365-2826.2003.00978.x

Kalbitzer, J., Frokjaer, V. G., Erritzoe, D., Svarer, C., Cumming, P. Nielsen, F. A., et al. (2009). The personality trait openness is related to cerebral 5-HTT levels. Neuroimage 45, 280-285. doi: 10.1016/j.neuroimage.2008.12.001

Karg, K., Burmeister, M., Shedden, K., and Sen, S. (2011). The serotonin transporter promoter variant (5-HTTLPR), stress, and depression meta-analysis revisited evidence of genetic moderation. Arch. Gen. Psychiatry 68, 444-454. doi: 10.1001/archgenpsychiatry.2010.189

Kazantseva, A. V., Gaysina, D. A. Faskhutdinova, G. G., Noskova, T. Malykh, S. B., and Khusnutdinova, E. K. (2008). Polymorphisms of the serotonin transporter gene (5-HTTLPR, A/G SNP in 5HTTLPR, and STin2 VNTR) and their relation to personality traits in healthy individuals from Russia. Psychiatr. Genet. 18, 167-176. doi: 10.1097/YPG.0b013e328304deb8

Klucken, T., Wehrum, S. Schweckendiek, J., Merz, C. J., Hennig, J., Vaitl, D., et al. (2012). The 5-HTTLPR polymorphism is associated with altered hemodynamic responses during appetitive conditioning. Hum. Brain Mapp. doi: 10.1002/ hbm.22085. [Epub ahead of print].

Kuepper, Y., Alexander, N., Osinsky, R., Mueller, E., Schmitz, A., Netter, P., et al. (2010). Aggressioninteractions of serotonin and testosterone in healthy men and women. Behav. Brain Research 206, 93-100. doi: 10.1016/j.bbr.2009.09.006

Kuepper, Y., Bausch, S., Iffland, J., Reuter, M., and Hennig, J.
(2006). S-Citalopram in neuroendocrine challenge-tests: serotonergic responsivity in healthy male and female human participants. Psychoneuroendocrinology 31, 1200-1207. doi: 10.1016/j.psyneuen.2006.09.001

Kuepper, Y., Wielpuetz, C., Alexander, N., Mueller, E., Grant, P., and Hennig, J. (2012). 5-HTTLPR Sallele: a genetic plasticity factor regarding the effects of life events on personality? Genes Brain Behav. 11, 643-650. doi: 10.1111/j.1601183X.2012.00783.x

Lesch, K. P., Bengel, D., Heils, A., Sabol, S. Z., Greenberg, B. D., Petri, S., et al. (1996). Association of anxiety-related traits with a polymorphism in the serotonin transporter gene regulatory region. Science 274, 1527-1531. doi: 10.1126/science.274.5292.1527

Lucki, I. (1998). The spectrum of behaviors influenced by serotonin. Biol. Psychiatry 44, 151-162. doi: 10.1016/S0006-3223(98)00139-5

Manuck, S. B., Flory, J. D., Ferrell, R. E., and Muldoon, M. F. (2004). Socio-economic status covaries with central nervous system serotonergic responsivity as a function of allelic variation in the serotonin transporter gene-linked polymorphic region. Psychoneuroendocrinology 29, 651-668. doi: 10.1016/S03064530(03)00094-5

Manuck, S. B., Flory, J. D., McCaffery, J. M., Matthews, K. A., Mann, J. J., and Muldoon, M. F. (1998). Aggression, impulsivity, and central nervous system serotonergic responsivity in a nonpatient sample. Neuropsychopharmacology 19, 287-299.

Margraf, J. (1994). Diagnostisches KurzInterview bei psychischen Störungen: Mini-DIPS. Berlin: Springer. doi: 10.1007/978-3-662-06753-6

Markus, C. R., and De Raedt, R. (2011). Differential effects of 5httlpr genotypes on inhibition of negative emotional information following acute stress exposure and tryptophan challenge. Neuropsychopharmacology 36, 819-826. doi: 10.1038/npp.2010. 221

Markus, C. R., and Firk, C. (2009). Differential effects of tri-Allelic 5HTTLPR polymorphisms in healthy subjects on mood and stress performance after tryptophan challenge. Neuropsychopharmacology 34, 2667-2674. doi: 10.1038/npp.2009. 92

Marsh, A. A., Finger, E. C., Buzas, B., Soliman, N., Richell, R. A., Vythilingham, M., et al. (2006). 
Impaired recognition of fear facial expressions in 5-HTTLPR S-polymorphism carriers following tryptophan depletion. Psychopharmacology 189, 387-394. doi: 10.1007/s00213-006-0581-2

McEwen, B. S. (2001). Genome and hormones: gender differences in physiology - invited review: estrogens effects on the brain: multiple sites and molecular mechanisms. J. Appl. Physiol. 91, 2785-2801.

Minelli, A., Bonvicini, C., Scassellati, C., Sartori, R., and Gennarelli, M. (2011). The influence of psychiatric screening in healthy populations selection: a new study and meta-analysis of functional 5HTTLPR and rs25531 polymorphisms and anxiety-related personality traits. BMC Psychiatry 11:50. doi: 10.1186/1471-244X-11-50

Munafo, M. R., Brown, S. M., and Hariri, A. R. (2008). Serotonin transporter (5-HTTLPR) genotype and amygdala activation: a meta-analysis. Biol. Psychiatry 63, 852-857. doi: 10.1016/j.biopsych.2007.08.016

Munafo, M. R., Clark, T. G., Moore, L. R., Payne, E., Walton, R., and Flint, J. (2003). Genetic polymorphisms and personality in healthy adults: a systematic review and metaanalysis. Mol. Psychiatry 8, 471-484. doi: 10.1038/sj.mp.4001326

Munafo, M. R., Clark, T. G., Roberts, K. H., and Johnstone, E. C. (2006). Neuroticism mediates the association of the serotonin transporter gene with lifetime major depression. Neuropsychobiology 53, 1-8. doi: $10.1159 / 000089915$

Munafo, M. R., Freimer, N. B., Ng, W., Ophoff, R., Veijola, J., Miettunen, J., et al. (2009). 5-HTTLPR genotype and anxiety-related personality traits: a meta-analysis and new data. Am. J. Med. Genet. B Neuropsychiatr. Genet. 150B, 271-281. doi: 10.1002/ajmg.b.30808 Murthy, N. V., Selvaraj, S., Cowen, P. J., Bhagwagar, Z., Riedel, W. J., Peers, P., et al. (2010). Serotonin transporter polymorphisms (SLC6A4 insertion/deletion and rs25531) do not affect the availability of 5-HTT to [C-11] DASB binding in the living human brain. Neuroimage 52, 50-54. doi: 10.1016/j.neuroimage.2010.04.032

Neumeister, A., Hu, X. Z., Luckenbaugh, D. A., Schwarz, M., Nugent, A. C., Bonne, O., et al. (2006). Differential effects of 5-HTTLPR genotypes on the behavioral and neural responses to tryptophan depletion in patients with major depression and controls.
Arch. Gen. Psychiatry 63, 978-986. doi: 10.1001/archpsyc.63.9.978

Nordquist, N., and Oreland, L. (2010). Serotonin, genetic variability, behaviour, and psychiatric disorders - a review. Ups. J. Med. Sci. 115, 2-10. doi 10.3109/03009730903573246

Owens, M. J., Knight, D. L., and Nemeroff, C. B. (2001). Second-generation SSRIs: human monoamine transporter binding profile of escitalopram and R-fluoxetine. Biol. Psychiatry 50, 345-350. doi: 10.1016/S0006-3223(01)01145-3

Parker, K. J., Buckmaster, C. L., Schatzberg, A. F., and Lyons, D. M. (2005). Intranasal oxytocin administration attenuates the ACTH stress response in monkeys. Psychoneuroendocrinology 30, 924-929. doi 10.1016/j.psyneuen.2005.04.002

Patrick, C. J., Curtin, J. J., and Tellegen, A. (2002). Development and validation of a brief form of the multidimensional personality questionnaire. Psychol. Assess. 14, 150-163. doi: 10.1037/1040-3590.14.2.150

Pergamin-Hight, L., BakermansKranenburg, M. J., van IJzendoorn, M. H., and Bar-Haim, Y. (2012). Variations in the promoter region of the serotonin transporter gene and biased attention for emotional information: a meta-analysis. Biol. Psychiatry 71, 373-379. doi: 10.1016/j.biopsych.2011.10.030

Pezawas, L., Meyer-Lindenberg, A., Drabant, E. M., Verchinski, B. A., Munoz, K. E., Kolachana, B. S., et al. (2005). 5-HTTLPR polymorphism impacts human cingulate-amygdala interactions: a genetic susceptibility mechanism for depression. Nat. Neurosci. 8, 828-834. doi: 10.1038/nn1463

Pluess, M., Belsky, J., Way, B. M. and Taylor, S. E. (2010). 5HTTLPR moderates effects of current life events on neuroticism: differential susceptibility to environmental influences. Prog. Neuropsychopharmacol. Biol. Psychiatry 34, 1070-1074. doi: 10.1016/j.pnpbp.2010.05.028

Praschak-Rieder, N., Kennedy, J., Wilson, A. A., Hussey, D., Boovariwala, A., Willeit, M., et al. (2007). Novel 5-HTTLPR allele associates with higher serotonin transporter binding in putamen: a [C-11] DASB positron emission tomography study. Biol. Psychiatry 62, 327-331. doi: 10.1016/j.biopsych.2006.09.022

Pruessner, J. C., Kirschbaum, C., Meinlschmid, G., and Hellhammer
D. H. (2003). Two formulas for computation of the area under the curve represent measures of total hormone concentration versus time-dependent change. Psychoneuroendocrinology 28 916-931. doi: 10.1016/S03064530(02)00108-7

Reimold, M., Smolka, M. N., Schumann, G., Zimmer, A. Wrase, J., Mann, K., et al. (2007). Midbrain serotonin transporter binding potential measured with [C-11]DASB is affected by serotonin transporter genotype. J. Neural Transm. 114, 635-639. doi: 10.1007/s00702-006-0609-0

Reist, C., Helmeste, D., Albers, L., Chhay, H., and Tang, S. W. (1996) Serotonin indices and impulsivity in normal volunteers. Psychiatry Res. 60, 177-184. doi: 10.1016/01651781(95)02830-7

Sen, S., Villafuerte, S., Nesse, R., Stoltenberg, S. F., Hopcian, J., Gleiberman, L., et al. (2004). Serotonin transporter and GABA(A) alpha 6 receptor variants are associated with neuroticism. Biol. Psychiatry 55, 244-249. doi 10.1016/j.biopsych.2003.08.006

Smith, G. S., Lotrich, F. E., Malhotra, A. K., Lee, A. T., Ma, Y. L. Kramer, E., et al. (2004). Effects of serotonin transporter promoter polymorphisms on serotonin function. Neuropsychopharmacology 29, 2226-2234. doi 10.1038/sj.npp. 1300552

Sogaard, B., Mengel, H., Rao, N., and Larsen, F. (2005). The pharmacokinetics of escitalopram after oral and intravenous administration of single and multiple doses to healthy subjects. J. Clin. Pharmacol. 45, 1400-1406. doi $10.1177 / 0091270005280860$

Spoont, M. R. (1992). Modulatory role of serotonin in neura information-processing - implications for human psychopathology. Psychol. Bull. 112, 330-350. doi 10.1037/0033-2909.112.2.330

Tatsumi, M., Groshan, K., Blakely, R. D., and Richelson, E. (1997). Pharmacological profile of antidepressants and related compounds at human monoamine transporters. Eur. J. Pharmacol. 340, 249-258. doi 10.1016/S0014-2999(97)01393-9

Taylor, S. E., Way, B. M., Welch, W. T., Hilmert, C. J., Lehman, B. J. and Eisenberger, N. I. (2006). Early family environment, current adversity, the serotonin transporter promoter polymorphism, and depressive symptomatology. Biol. Psychiatry 60, 671-676. doi 10.1016/j.biopsych.2006.04.019
Tellegen, A. (1985). "Structures of mood and personality and their relevance to assessing anxiety, with an emphasis on self-report," in Anxiety and the Anxiety Disorders, ed A. H. Tuma and, J. Maser (Hillsdale, NY: Lawrence Erlbaum Associates), 681-706.

Tellegen, A., and Waller, N. G. (2008) "Exploring personality through test construction: development of the multidimensional personality questionnaire," in Handbook of Personality Theory and Testing: Personality Measurement and Assessment, Vol. 2, ed G. J. Boyle, G. Matthews, and D. H. Saklofske (Greenwich, CT: JAI Press), 261-292.

Terracciano, A., Tanaka, T., Sutin, A. R., Deiana, B., Balaci, L., Sanna, S., et al. (2010). BDNF Val66Met is associated with introversion and interacts with 5-HTTLPR to influence neuroticism. Neuropsychopharmacology 35, 1083-1089. doi 10.1038/npp.2009.213

Uher, R., and McGuffin, P. (2008). The moderation by the serotonin transporter gene of environmental adversity in the aetiology of mental illness: review and methodological analysis. Mol. Psychiatry 13, 131-146. doi: 10.1038/sj.mp.4002067

Uvnas-Moberg, K., Bjorkstrand, E., Hillegaart, V., and Ahlenius, S. (1999). Oxytocin as a possible mediator of SSRIinduced antidepressant effects. Psychopharmacology 142, 95-101. doi: 10.1007/s002130050867

Watson, D., Clark, L. A., and Tellegen, A. (1988). Development and validation of brief measures of positive and negative affect - the panas scales. J. Pers. Soc. Psychol. 54, 1063-1070. doi: 10.1037/00223514.54.6.1063

Whale, R., Quested, D. J., Laver, D., Harrison, P. J., and Cowen, P. J. (2000). Serotonin transporter (5-HTT) promoter genotype may influence the prolactin response to clomipramine. Psychopharmacology 150, 120-122. doi: 10.1007/s002130000432

Whitaker-Azmitia, P. M. (2005). Behavioral and cellular consequences of increasing serotonergic activity during brain development: a role in autism? Int. J. Dev. Neurosci. 23, 75-83. doi: 10.1016/j.ijdevneu.2004.07.022

Willeit, M., and Praschak-Rieder, N. (2010). Imaging the effects of genetic polymorphisms on radioligand binding in the living human brain: a review on 
genetic neuroreceptor imaging of monoaminergic systems in psychiatry. Neuroimage 53, 878-892. doi: 10.1016/j.neuroimage.2010.04.030

Windle, R. J., Shanks, N., Lightman, S. L., and Ingram, C. D. (1997). Central oxytocin administration reduces stress-induced corticosterone release and anxiety behavior in rats. Endocrinology 138, 2829-2834. doi: 10.1210/en.138.7.2829

Wong, W. M., Hasemann, S., Schwarz, M., Zill, P., Koller, G., Soyka, M., et al. (2008). Citalopram neuropharmacological challenge in alcohol-dependent patients and controls: pharmacogenetic, endocrine and psychobehavioral results. Pharmacopsychiatry 41, 72-78. doi: 10.1055/s-2007-1004595

Yatham, L. N., and Steiner, M. (1993). Neuroendocrine probes of serotonergic function a critical-review. Life Sci. 53, 447-463. doi: 10.1016/0024-3205 (93)90696-Z

Zald, D. H., and Depue, R. A. (2001). Serotonergic functioning correlates with positive and negative affect in psychiatrically healthy males. Pers. Individ. Differ. 30, 71-86. doi: 10.1016/S0191-8869(00)00011-8
Conflict of Interest Statement: The authors declare that the research was conducted in the absence of any commercial or financial relationships that could be construed as a potential conflict of interest.

Received: 07 May 2013; paper pending published: 18 June 2013; accepted: 01 August 2013; published online: 23 August 2013.

Citation: Wielpuetz C, Kuepper Y, Grant $P$, Munk AJL and Hennig J (2013) Acute responsivity of the serotonergic system to $S$-citalopram and positive emotionality - the moderating role of the 5-HTTLPR. Front. Hum.
Neurosci. 7:486. doi: 10.3389/fnhum. 2013.00486

This article was submitted to the journal Frontiers in Human Neuroscience.

Copyright (c) 2013 Wielpuetz, Kuepper, Grant, Munk and Hennig. This is an open-access article distributed under the terms of the Creative Commons Attribution License (CC BY). The use, distribution or reproduction in other forums is permitted, provided the original author(s) or licensor are credited and that the original publication in this journal is cited, in accordance with accepted academic practice. No use, distribution or reproduction is permitted which does not comply with these terms. 